\title{
Early emotional processing deficits in depersonalization: An exploration with event-related potentials in an undergraduate sample
}

Citation for published version (APA):

Quaedflieg, C. W. E. M., Giesbrecht, T., Meijer, E., Merckelbach, H., de Jong, P. J. ., Thorsteinsson, H., Smeets, T., \& Simeon, D. (2013). Early emotional processing deficits in depersonalization: An exploration with event-related potentials in an undergraduate sample. Psychiatry Research, 212(3), 223-229. https://doi.org/10.1016/j.pscychresns.2012.08.001

Document status and date:

Published: 30/06/2013

DOI:

10.1016/j.pscychresns.2012.08.001

Document Version:

Publisher's PDF, also known as Version of record

Document license:

Taverne

Please check the document version of this publication:

- A submitted manuscript is the version of the article upon submission and before peer-review. There can be important differences between the submitted version and the official published version of record.

People interested in the research are advised to contact the author for the final version of the publication, or visit the DOI to the publisher's website.

- The final author version and the galley proof are versions of the publication after peer review.

- The final published version features the final layout of the paper including the volume, issue and page numbers.

Link to publication

\footnotetext{
General rights rights.

- You may freely distribute the URL identifying the publication in the public portal. please follow below link for the End User Agreement:

www.umlib.nl/taverne-license

Take down policy

If you believe that this document breaches copyright please contact us at:

repository@maastrichtuniversity.nl

providing details and we will investigate your claim.
}

Copyright and moral rights for the publications made accessible in the public portal are retained by the authors and/or other copyright owners and it is a condition of accessing publications that users recognise and abide by the legal requirements associated with these

- Users may download and print one copy of any publication from the public portal for the purpose of private study or research.

- You may not further distribute the material or use it for any profit-making activity or commercial gain

If the publication is distributed under the terms of Article $25 \mathrm{fa}$ of the Dutch Copyright Act, indicated by the "Taverne" license above, 


\title{
Early emotional processing deficits in depersonalization: An exploration with event-related potentials in an undergraduate sample
}

\author{
Conny W.E.M. Quaedflieg a,*, Timo Giesbrecht ${ }^{\mathrm{a}}$, Ewout Meijer ${ }^{\mathrm{a}}$, Harald Merckelbach ${ }^{\mathrm{a}}$, Peter J. de Jong ${ }^{\mathrm{b}}$, \\ Haraldur Thorsteinsson ${ }^{\mathrm{b}}$, Tom Smeets $^{\mathrm{a}}$, Daphne Simeon ${ }^{\mathrm{c}}$ \\ a Faculty of Psychology and Neuroscience, Maastricht University, the Netherlands \\ ${ }^{\mathrm{b}}$ Department of Clinical Psychology and Experimental Psychopathology, University of Groningen, the Netherlands \\ ${ }^{\mathrm{c}}$ Department of Psychiatry, Beth Israel Medical Center, New York, NY, USA
}

\section{A R T I C L E I N F O}

\section{Article history:}

Received 18 July 2011

Received in revised form

27 July 2012

Accepted 2 August 2012

\section{Keywords:}

Emotion-induced blindness (EIB)

Depersonalization symptoms

Rapid serial visual presentation (RSVP)

paradigm

International Affective Picture System (IAPS)

\begin{abstract}
A B S T R A C T
Emotional stimuli may draw attention to such an extent that they hamper the processing of subsequent signals, a phenomenon termed emotion-induced blindness (EIB). As depersonalization is associated with selfreported attenuated emotional responses, the present study explored whether individuals scoring high on the Cambridge Depersonalization Scale (CDS; $n=15$ ) exhibit a diminished EIB effect relative to low CDS scoring individuals $(n=15)$, and whether attentional processes reflected in event-related potentials (ERPs) are implicated in this effect. We obtained an EIB effect such that emotional distractors that preceded targets with a lag of $200 \mathrm{~ms}$ reduced correct detection of targets. Although the magnitude of this effect was similar for high and low CDS participants, high CDS participants exhibited a significantly lower ERP amplitude at the frontal lead in the 200-300 ms window than did low CDS individuals to targets that followed emotional versus neutral distractors. This latter effect was significantly related to the Alienation factor of the CDS. This pattern suggests that difficulties in the discrimination between emotional and neutral stimuli relate to the feeling of unreality in depersonalization.
\end{abstract}

(c) 2012 Elsevier Ireland Ltd. All rights reserved.

\section{Introduction}

Emotionally salient stimuli tend to capture and hold attention. This characteristic helps us to prioritize information processing in an increasingly complex world (Nummenmaa et al., 2006; Vuilleumier, 2005; Schupp et al., 2006). Most et al. (2005) demonstrated that the attention-grabbing and -holding capabilities of emotional stimuli are so profound that attention remains focused even after the offset of the emotional stimuli. Specifically, these authors showed that individuals performed substantially worse at correctly perceiving target stimuli when these targets were preceded by an emotionally aversive distractor, a phenomenon dubbed emotion-induced blindness (EIB).

Evidence showing that emotional stimulus value helps us to focus our limited amount of attention to potentially relevant stimuli is abundant. However, one may wonder whether this is also true for individuals suffering from depersonalization and derealization, as these individuals report a lack of emotional responsivity to other people or external events (e.g., objects) (Simeon, 2004) and

\footnotetext{
* Correspondence to: Conny Quaedflieg, Faculty of Psychology and Neuroscience, Maastricht University, PO Box 616, 6200 MD, Maastricht, the Netherlands. Tel.: +31 43388 4536, fax: +31433884196.

E-mail address: conny.quaedflieg@maastrichtuniversity.nl (C.W.E.M. Quaedflieg).
}

concomitant high levels of internal distress and anxiety (Simeon and Abugel, 2006). The Diagnostic and Statistical Manual of Mental Disorders (DSM IV-TR; American Psychiatric Association, 2000) describes depersonalization and derealization as "an alteration in the perception or experience of the self so that one feels detached from, and as if one is an outside observer of, one's mental processes or body (e.g., feeling as in a dream)" and "an alteration in the perception or experience of the external world so that it seems strange or unreal (e.g., people seem unfamiliar)", respectively. ${ }^{1}$ Transient experiences of depersonalization are common in the general population, with a prevalence of about $19 \%$ as found in a representative telephone survey that measured the self-reported presence of DSM-IV criteria for DPD/DR during the last 12 months (Aderibigbe et al., 2001). However, when depersonalization becomes persistent or recurrent and is associated with significant distress and/or impairment, a diagnosis of Depersonalization Disorder (DPD) should be considered. Using the Present State Examination, the prevalence of DPD was estimated to be $0.95 \%$ in a recent population-based birth cohort from the UK (Lee et al., 2012).

Although pertinent research into the cognitive impairments associated with depersonalization is limited (Giesbrecht et al.,

\footnotetext{
${ }^{1}$ Depersonalization and derealization are highly related to each other, which is why, in line with common practice in the literature, we will use the term depersonalization as encompassing both phenomena.
} 
2008a), robust evidence both on the behavioral and on the neurobiological level shows that DPD goes along with deficits in emotion processing. On the behavioral level, two factor analytic studies addressing the Cambridge Depersonalization Scale (CDS), a self-report questionnaire measuring DPD symptoms, identified five unique subscales of which emotional numbing explained the largest proportion of variance in CDS scores (Sierra et al., 2005; Simeon et al., 2008). Further support for a deficit in the normal discrimination between emotional and neutral material comes from imaging and autonomic response studies. For example, Sierra et al. (2002b) showed that DPD patients exhibit reduced skin conductance responsivity (SCR) to emotionally aversive, but not unspecific, stimuli compared with both normal controls and anxiety disordered patients. This finding is underlined by data from our laboratory showing that in DPD patients the time course of physiological responding to an emotionally negative video differs profoundly from that typical for normal controls. That is to say, patients exhibit a reduced latency of SCRs in combination with a subsequent flattening of responses (Giesbrecht et al., 2010). Germane to this are also experimental studies on dissociation indicating that high levels of dissociation are associated with rapid habituation of the SCR. For example, Giesbrecht et al. (2008b) noted that students with heightened acute dissociation as indexed by the Peritraumatic Dissociative Experiences questionnaire (PDEQ) showed a relatively fast habituation of SCR, defined by the occurrence of two consecutive non-response SCR trials ( $<0.05$ microsiemens), to aversive auditory stimuli.

Using functional magnetic resonance imaging (fMRI), Medford et al. (2006) demonstrated that in contrast to findings in healthy controls, encoding of emotional and neutral words did not lead to differential patterns of brain activation in patients with DPD. Both emotional and neutral words were processed in a highly similar manner in this group. Behaviorally, the patients exhibited better memory for aversive as compared to neutral words, but there was no enhancement of memory for neutral words in an aversive context compared to a neutral context. More strikingly, in another study, DPD patients rated aversive stimuli as equally emotional as the neutral scenes (Phillips et al., 2001). These ratings went along with increased activation in the right ventral prefrontal cortex (Brodmann area (BA) 47), but not the left insula in response to aversive scenes compared to healthy controls and patients with Obsessivecompulsive disorder. This is of particular relevance as the ventrolateral right prefrontal cortex, an area involved in appraisal and regulation of emotion, inhibits the insula, an emotion sensitive area especially for negative emotions and disgust (Phillips et al., 2001). This pattern of findings is consistent with the view of selective inhibition of emotion processing or a emotional shut-down mechanism that some researchers have postulated to be typical for dissociation in general and depersonalization in particular (Sierra and Berrios, 1998; Giesbrecht et al., 2008b).

The EIB is a behavioral phenomenon that only demonstrates visual processing impairments without unveiling the underlying biological mechanism. Skin conductance measurements to some extent capture this mechanism, but merely index overall physiological arousal. Whereas changes in metabolism or blood flow are indirect reflections of neuronal activity, electroencephalography (EEG) can provide direct real-time information about ongoing cerebral processes. One way to expand the current corpus of knowledge on emotion processing and depersonalization symptoms is to use event related potentials (ERPs) obtained using EEG. ERPs reflect cortical information processing and have widely been used to study emotion and attention (Cacioppo et al., 2007; Luck et al., 2000; Schupp et al., 2006).

The present study aimed to further investigate emotion processing in depersonalization by combining the EIB paradigm with an ERP approach. More specifically, we explored how a tendency to experience depersonalization symptoms affects the time course of disengagement from emotional stimuli at the behavioral level (as reflected in the EIB effect) and at the electrophysiological level (reflected in ERP indices of early attentional processing and emotional arousal). To isolate ERP responses, difference waves to targets were calculated by subtracting ERPs to targets that followed neutral distractors from ERPs to targets that followed emotional distracters (Luck et al., 2000). This corrects for the overlap of stimuli in the rapid serial visual presentation (RSVP) paradigm and enables isolation of the ERPs for targets due to the well-known affect and arousal sensitivity of EEG components.

To the extent that individuals with a heightened tendency to depersonalize exhibit a blunted processing of emotional stimuli, one would expect these individuals to demonstrate a less pronounced EIB effect quantified by the correct detection rates of targets following emotional stimuli. Second, to the extent that blunted emotion processing associated with depersonalization is related to early attention and emotional arousal mechanisms, one would expect this to be reflected in the ERPs of persons scoring high on depersonalization. Specifically, we predicted that participants scoring high on depersonalization would exhibit a smaller difference in ERP amplitude to targets that followed emotional versus neutral distractors compared with participants scoring low on depersonalization. Finding such a pattern would provide insight into time course of disengagement from emotional stimuli in depersonalization.

\section{Methods}

\subsection{Participants}

During mass testing sessions $(N=310)$, undergraduate students enrolled at Maastricht University filled out the Cambridge Depersonalization Scale (CDS Sierra and Berrios, 2000; see below). For the current study, students with CDS scores below 55 or above 80 were invited to volunteer as participants. The overwhelming majority of participants, who were invited to participate, agreed to volunteer in this study. They were given a financial compensation or partial course credit. Cut-off scores were based on Sierra and Berrios' (2000) suggestion to use a cutting score of 70 for the detection of DPD. The sample comprised 15 lowdepersonalization individuals and 15 high-depersonalization individuals. ${ }^{2}$ The two groups did not differ in terms of age (see Table 1) and were matched in terms of gender, with both groups containing 11 women. The study was approved by the standing ethical committee of the Faculty of Psychology and Neuroscience, Maastricht University, and all participants were naïve as to the purpose of the study.

\subsection{Measures}

Cambridge Depersonalization Scale (CDS; Cronbach's alpha $=0.95$; Sierra and Berrios, 2000). The CDS consists of 29 items that require respondents to rate depersonalization symptoms over the "last 6 months" on a 5-point frequency scale (anchors: $0=$ never; $4=$ all the time) and a 6-point duration scale (anchors: $1=\mathrm{a}$ few seconds; $6=$ more than $a$ week). All CDS frequency and duration scores are summed to obtain a total score. The scale is able to differentiate between patients with DPD and patients with anxiety disorders, patients with temporal lobe epilepsy, and healthy controls. Sierra and Berrios (2000) report sound psychometric properties for the CDS. In a factor analytic study, Sierra et al. (2005) identified four CDS subscales: Anomalous Body Experiences (e.g., "I have to touch myself to make sure that I have a body or a real existence."), Emotional Numbing (e.g., "When I weep or laugh, I do not seem to feel any emotions at all.") Anomalous Subjective Recall (e.g., "It seems as if things that I have recently done had taken place a long time ago."), and Alienation from Surrounding (e.g., "Out of the blue, I feel strange, as if I were not real or as if I were cut off from the world.").

Dissociative Experiences Scale (DES; Cronbach's alpha=0.92; Bernstein and Putnam, 1993). The DES is a 28 -item self-report scale that asks respondents to indicate the frequency of various dissociative experiences rated on $0 \%$ to $100 \%$ visual-analogue

${ }^{2}$ One high-depersonalization participant performed just about chance leve (mean accuracy $=61 \%, 3.13$ SD's below the mean) on the Emotional Scenes Task probably indicating a lack of motivation. This participant was excluded from the study and another participant was recruited to replace the excluded participant. 
Table 1

Mean levels $(S D)$ and statistical comparison of age, depersonalization (CDS) dissociation (DES), anxiety (STAI-T), depression (BDI), and childhood trauma (CTQ) scores for high and low depersonalization individuals (each $n=15$ ).

\begin{tabular}{|c|c|c|c|c|c|}
\hline Variable & $\begin{array}{l}\text { Low } \\
\text { Depersonalization } \\
(n=15) \\
\text { Mean (SD) }\end{array}$ & $\begin{array}{l}\text { High } \\
\text { Depersonalization } \\
(n=15) \\
\text { Mean (SD) }\end{array}$ & $t$ & $d f$ & $p$ \\
\hline $\begin{array}{l}\text { Age } \\
\text { (years) }\end{array}$ & $19.80(1.57)$ & 19.93 (2.09) & 0.20 & 28 & 0.84 \\
\hline CDS & $36.21(12.21)$ & 99.97 (17.05) & 11.77 & 28 & $<0.01$ \\
\hline DES & $12.37(6.52)$ & $22.35(12.24)$ & 2.79 & 28 & $<0.01$ \\
\hline STAI-T & $37.13(7.37)$ & $43.07(8.81)$ & 1.97 & 27 & 0.06 \\
\hline BDI & $3.40(2.84)$ & $8.93(6.76)$ & 2.31 & 27 & $<0.05$ \\
\hline CTQ & $29.20(5.65)$ & $39.00(11.86)$ & 2.77 & 28 & $<0.01$ \\
\hline
\end{tabular}

Note: CDS, Cambridge Depersonalization Scale; DES, Dissociative Experiences Scale; STAI-T, State-Trait Anxiety Inventory-Trait; BDI, Beck Depression Inventory; CTQ, Childhood Trauma Questionnaire.

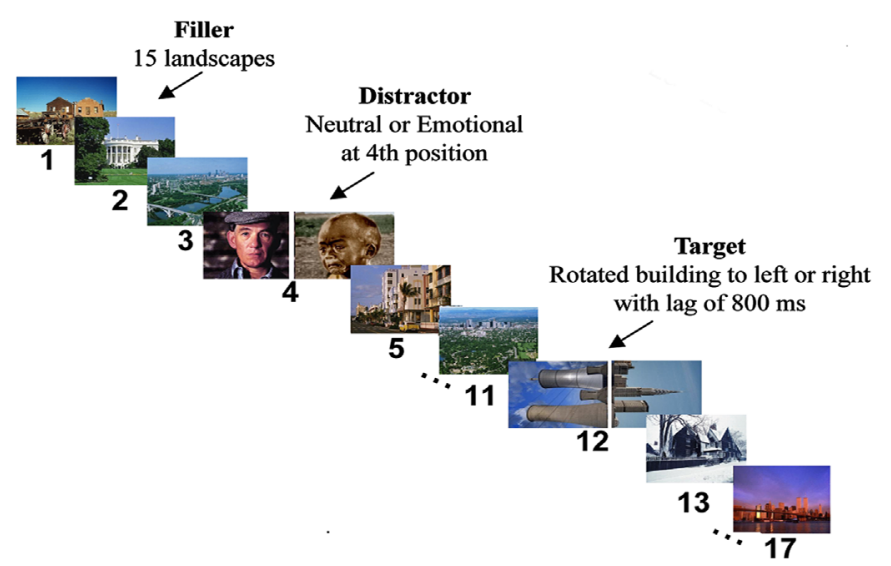

Fig. 1. Example of a 17-item RSVP trial. Each stream consists of 1 distractor 1 target, and 15 fillers presented for $100 \mathrm{~ms}$. Distractors are presented at the 4 th, 6 th or 8th position. Here, the distractor is presented at the 4th position. Targets are presented with a lag of 2 or 8 pictures, i.e., 200 or $800 \mathrm{~ms}$ after distractor offset. The $800 \mathrm{~ms}$ time lag is displayed. Note that in the -100 lag condition the distractor was presented after rather than before the target, as is displayed here.

scales. In a meta-analytic study, van IJzendoorn and Schuengel (1996) provided evidence for the sound psychometric properties of the DES. A sample item is "Some people have the experience of looking in a mirror and not recognizing themselves. Mark the line to show what percentage of the time this happens to you."

Childhood Trauma Questionnaire (CTQ; Cronbach's alpha=0.83; Bernstein et al. 2003). The CTQ is a widely used self-report scale of childhood interpersona trauma, rated on a 5-point scale. In the present study, we employed the short form that consists of 25 items and for which Bernstein et al. (2003) reported satisfactory psychometric qualities. Illustrative items are "There was enough food in the house for everyone" and "Someone tried to touch me in a sexual way or make me touch them". The CTQ was included in the present study to explore whether self reported emotional abuse or neglect might affect the experimental effects (see, e.g., Simeon et al., 2001).

Beck Depression Inventory (BDI; Cronbach's alpha=0.96; Beck et al., 1961). The $\mathrm{BDI}$ is a 21-item multiple-choice self-report inventory that measures the presence and degree of depression in adolescents and adults. It is composed of items relating to depressive symptoms such as hopelessness and irritability, cognitions such as guilt or feelings of being punished, as well as physical symptoms such as fatigue, weight loss, and lack of interest in sex. The BDI is one of the most widely used self-report measures of depression.

State-Trait Anxiety Inventory-Trait Form (STAI-T; Cronbach's alpha $=0.88$; Spielberger, 1983). The STAI-T intends to tap anxiety proneness. It consists of 20 items asking respondents whether they generally experience various anxiety symptoms on 4 -point scales (anchors: 1 =almost never; 4 =almost always). The STAI has been widely used and possesses sound psychometric properties.

Emotional Scenes Task (EST; Most et al., 2005). The EST consists of a RSVP stream of 17 pictures presented for $100 \mathrm{~ms}$ each. Each picture presented in this stream belongs to one of three categories: distractors, fillers or targets. The distractors were either emotionally negative or neutral pictures ( $n=72$ each; drawn from the International Affective Picture System; IAPS; Lang et al., 1999). In total, 384 pictures of landscapes served as fillers, while 144 target pictures (photos depicting buildings rotated $90^{\circ}$ to the left or right; see Most et al., 2005, experiment 2, specific condition) served as targets. Each stream contained one distractor, one target, and 15 fillers. Distractors were presented at the 4th, 6th, or 8 th position and were followed by a target with a lag of 2 or 8 pictures, i.e., 200 or $800 \mathrm{~ms}$ after distractor offset. The task consisted of two blocks with 144 streams, each with the first and the second block using the same set of stimuli. After each stream, the participant indicated whether the target was rotated to the left or to the right by pressing one of two buttons. Moreover, a condition where targets directly preceded distractors was added. This condition was added to investigate whether emotional stimuli can also disrupt processing of targets in a retrograde rather than anterograde fashion. Finding such a pattern could possibly add to our understanding memory difficulties associated with peritraumatic dissociation. Fig. 1 shows an example of a RSVP trial. The outcome measure of EIB, the difference in target detection between emotional and neutral distractors, is the mean accuracy defined as proportion correct responses in percentage. No trials without distractors were included so as to maximize the number of trials available for the analysis of the event-related potentials. Stimuli assignment and order of trials were randomized.

\subsection{Material and procedure}

On arrival, participants were informed that EEG was to be measured. They were shown the control room with its equipment and the sound-attenuated testing room. After they gave informed consent, participants completed the DES, CTQ, BDI, and STAI-T while electrodes were applied. After participants had completed an unrelated cognitive task (the results of which will be reported elsewhere), the EST was administered. Finally, participants were thanked and fully debriefed.

\subsection{EEG recording, data reduction, and analysis}

Using Psylab software and Contact Precision Instruments amplifiers, electroencephalographic activity was recorded continuously with $\mathrm{Ag} / \mathrm{AgCl}$ electrodes from 3 scalp midline sites ( $\mathrm{Fz}, \mathrm{Cz} \& \mathrm{Pz}$ ) and the right mastoid according to the international 10-20 system. The left mastoid served as the reference for all electrodes and the forehead was grounded. To facilitate artifact-correction of the EEG, $\mathrm{Ag} / \mathrm{AgCl}$ electrodes were used to bipolarly record the vertical (above and below the left eye) and horizontal (at outer canthi of both eyes) electro-oculogram (EOG). EEG and EOG electrode impedances were below $5 \mathrm{k} \Omega$ and $10 \mathrm{k} \Omega$, respectively. EEG and EOG were filtered online with a band pass of $0.1-30 \mathrm{~Hz}$. EEG was amplified 20,000 times, EOG 4000, and digitized at $200 \mathrm{~Hz}$.

The EEG electrodes were re-referenced offline to the average of right and left mastoids (Miller et al., 1991; Hagemann, 2004). Ocular activity was removed using a regression procedure (Semlitsch et al., 1986) performed on the continuous data. After this, epochs were extracted from the continuous data, lasting from $100 \mathrm{~ms}$ before until $1000 \mathrm{~ms}$ after target onset. To ensure a reliable artifact rejection, these epochs were baseline adjusted baseline by subtracting the average activity in the $100 \mathrm{~ms}$ interval before stimulus onset, after which all trials containing amplitudes exceeding $\pm 50 \mu \mathrm{V}$ were removed. To delineate target ERPs, difference waves to targets were obtained by subtracting ERPs to targets that followed neutral distractors from ERPs to targets that followed emotional distracters. Next, grand average difference wave ERPs were calculated and mean ERP amplitudes were computed for windows with durations of $100 \mathrm{~ms}$ (i.e., stimulus duration) beginning at stimulus onset. EEG data were processed using EEGLAB 6 (Delorme and Makeig, 2004). In all statistical analysis, Greenhouse-Geisser corrected p-values are reported when sphericity assumptions were violated.

\section{Results}

\subsection{Self-report measures}

Mean scores on self-report measures for high and low depersonalization individuals are presented in Table 1 . The $t$-test indicated that high depersonalization individuals differed significantly from low depersonalization individuals on our measure of dissociation (i.e., DES) $[t(29)=2.79, p<0.01]$. This underscores the integrity of the dissociative symptoms reported by the depersonalization group. Moreover, compared with low depersonalization individuals, high depersonalization individuals scored significantly higher on the BDI and CTQ [all p's $<0.01$ ], but not on the STAI-T (see Table 1). 


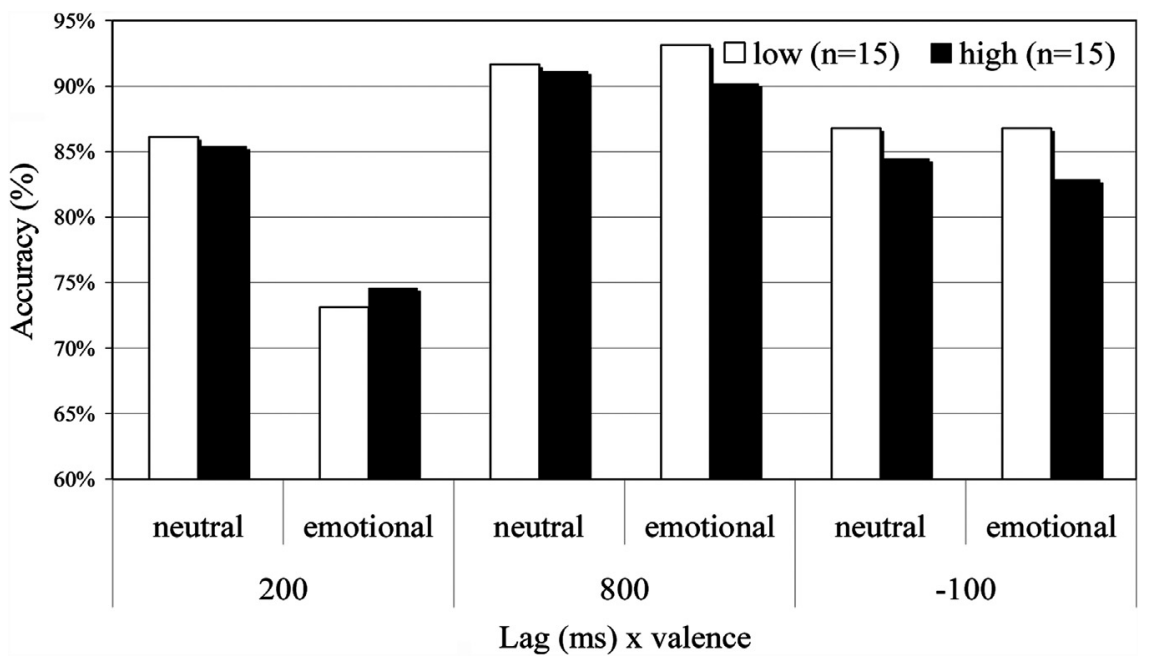

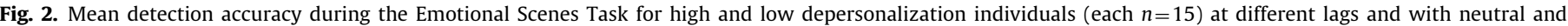
emotional distractors.

\subsection{Detection accuracy}

Fig. 2 presents detection accuracy (i.e., proportion correct in percentage) on the EST. To investigate the success of our manipulation a 3 (lag: $200 \mathrm{~ms}, 800 \mathrm{~ms}$, and $-100 \mathrm{~ms}$ ) $\times 2$ (valence: negative $\times$ neutral) repeated measures Analysis of Variance (ANOVA) on detection accuracy with both factors being within-subject factors was conducted. This yielded the critical lag $\times$ valence interaction $[F(2,29)=29.02, \quad p<0.001]$. Follow-up multiple comparisons demonstrated that this interaction was due to detection accuracy being poorer when the target was preceded by an emotional distractor with a lag of $200 \mathrm{~ms}$ as compared to a neutral distractor with a lag of $200 \mathrm{~ms}[t(29)=7.99, p<0.001]$, but such difference was not evident for emotional distractors versus neutral distractors with a lag of $800 \mathrm{~ms}[t(29)=-0.25, p>0.05]$ or for the condition in which targets were directly followed by distractors $(-100 \mathrm{~ms} \mathrm{lag})$ $[t(29)=0.60, p>0.05]$. Note that an EIB effect occurring at a lag of $200 \mathrm{~ms}$, but not at $800 \mathrm{~ms}$ corresponds with the findings of Most et al. (2005). Thus, following these authors' approach, the EIB effect was operationalized as the difference in accuracy between the neutral and emotional condition at lag $200 \mathrm{~ms}$. Therefore, we limited all subsequent analyses to targets preceded by distractors with a lag of $200 \mathrm{~ms}$.

The low and the high depersonalization group exhibited an EIB effect of $M=13 \%(S D=8 \%)$ and $M=10 \%(S D=8 \%)$, respectively with higher percentages representing a more pronounced EIB effect. A Mann-Whitney $U$ test was conducted comparing the two groups with respect to the EIB effect. This analysis failed to demonstrate a significant group difference $[z=-0.52, p>0.05]$. Moreover, Pearson correlations between the EIB, DES, CTQ, BDI, and STAI-T were all small and non-significant (see Table 2). RT times were analyzed using a 2(Group: low, high) $\times 2$ (Cue valence: neutral, emotional) Analysis of Variance (ANOVA), with the latter factor being a repeated measure. This revealed no significant interaction $[F(1,28)=1.551, p=0.223)$, indicating that the groups did not differ in used strategy.

\subsection{Event-related potentials}

Fig. 3 displays difference waves for targets preceded by neutral and emotional distractors for both groups separately. To investigate to what extent differences in cortical activation were associated with the EIB effect, Pearson correlations between the (behavioral) EIB and the differences in EEG activation were calculated (see
Table 2

Correlations between depersonalization (CDS), dissociation (DES), anxiety (STAI$\mathrm{T}$ ), depression (BDI), and childhood trauma (CTQ) scores and emotion induced blindness (EIB), and event-related potentials at $\mathrm{Fz}, \mathrm{Cz}$, and $\mathrm{Pz}$ within the 200$300 \mathrm{~ms} 500-600 \mathrm{~ms}$, and $600-700 \mathrm{~ms}$ windows across all participants $(N=30)$.

\begin{tabular}{llrrrrr}
\hline & & DES & \multicolumn{1}{l}{ STAI } & \multicolumn{1}{l}{ BDI } & CTQ & EIB \\
\hline EIB & $\begin{array}{l}\text { Behavioral } \\
\text { (ms) }\end{array}$ & -0.24 & -0.05 & -0.06 & 0.09 & - \\
ERP & & & & & & \\
Fz & $200-300$ & 0.24 & 0.20 & 0.28 & 0.07 & $-0.42^{*}$ \\
& $500-600$ & -0.15 & -0.15 & -0.07 & 0.09 & 0.26 \\
& $600-700$ & 0.09 & $0.38^{*}$ & $0.41^{*}$ & 0.25 & 0.28 \\
Cz & $200-300$ & 0.10 & -0.21 & -0.11 & -0.04 & $-0.51^{*}$ \\
& $500-600$ & -0.25 & -0.26 & -0.20 & 0.07 & 0.13 \\
& $600-700$ & -0.04 & 0.28 & 0.27 & 0.16 & 0.17 \\
Pz & $200-300$ & -0.05 & -0.29 & -0.28 & -0.02 & -0.31 \\
& $500-600$ & -0.21 & -0.32 & -0.28 & 0.07 & 0.00 \\
& $600-700$ & 0.03 & 0.14 & 0.15 & 0.13 & 0.03
\end{tabular}

Note: DES, Dissociative Experiences Scale; STAI-T, State-Trait Anxiety InventoryTrait; BDI,Beck Depression Inventory; CTQ Childhood Trauma Questionnaire; DES $\&$ CTQ $\mathrm{df}=28$; STAI \& BDI df $=27$; all ERPs $\mathrm{df}=28 ;{ }^{*} p<0.05$ (2-tailed).

Table 2). Differences in early activation in the window of 200$300 \mathrm{~ms}$ after target presentation were related to the magnitude of the EIB effect at $\mathrm{Cz}(r=-0.51, p<0.01)$ and $\mathrm{Fz}(r=-0.42, p<0.05)$. Specifically, when differences in activation are more pronounced, indicated by a larger difference wave value, the EIB effect increases. This finding indicates a meaningful relationship between the EIB effect and emotional minus neutral difference wave ERPs. All other correlations, including the window of 500-600 ms and 600-700 ms, were non-significant (see Table 2).

The effect of emotion on target processing in the $100 \mathrm{~ms}$ windows was analysed using a 3 (Electrode: $\mathrm{Fz}, \mathrm{Cz}, \mathrm{Pz}$ ) $\times 2$ (Cue valence: neutral, emotional) $\times 10$ (Time: $0-100 \mathrm{~ms}, 100-200 \mathrm{~ms}, 200-300 \mathrm{~ms}$, $300-400 \mathrm{~ms}, 400-500 \mathrm{~ms}, 500-600 \mathrm{~ms}, 600-700 \mathrm{~ms}, 700-800 \mathrm{~ms}$, $800-900 \mathrm{~ms}, 900-1000 \mathrm{~ms}$ ) repeated measures analysis of variance (ANOVA). As this yielded a significant electrode $\times$ cue $\times$ time interaction $[F(4.159,120.608)=9.350, p<0.001]$, separate ANOVAs for each electrode with cue valence (2 levels) and time (10 levels) as withinsubject factors were conducted. For all electrodes, a time $\times$ cue interaction was found [Fz: $F(3.387,98.216)=3.322, p<0.05 ; \mathrm{Cz}$ : $F(4.293,124.494)=8.622, p<0.001 ; P z: F(3.943,114.360)=11.142$, $p<0.001$ ] indicating that the emotion effect on targets differed between time windows and electrodes. Paired $t$-tests per time window per electrode revealed an emotion effect in following 

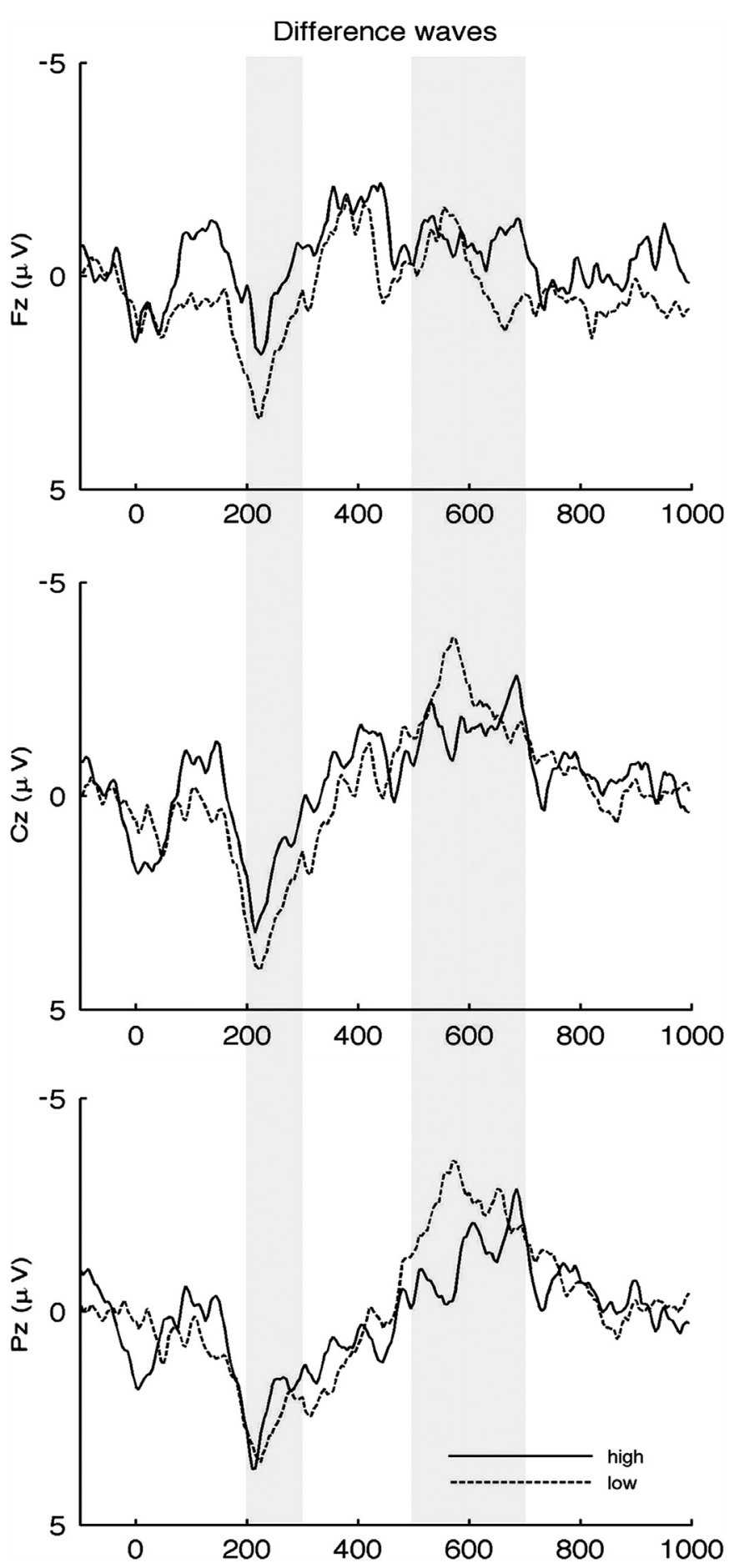

Fig. 3. Grand average difference waves event-related potentials to target stimuli preceded by neutral and emotional distractors for participants scoring high and low on depersonalization ( $n=15$ each) for the midline electrode sites Fz, Cz, and Pz.

windows: $0-100 \mathrm{~ms}, 200-300 \mathrm{~ms}, 500-600 \mathrm{~ms}$, and $600-700 \mathrm{~ms}^{3}$. The high and low depersonalisation groups were then compared in

\footnotetext{
${ }^{3}$ The emotion effect on target processing was tested in all $100 \mathrm{~ms}$ time windows on all electrodes. Paired $t$-tests yielded the following significant windows: Fz: 0 $100 \mathrm{~ms}[t(29)=-2.089, p<0.05], 200-300 \mathrm{~ms}[t(29)=-3.198, p<0.01] ; \mathrm{Cz}: 0$ $100 \mathrm{~ms}[t(29)=-2.730, p<0.05], 200-300 \mathrm{~ms}[t(29)=-5.185, p<0.01], 500$ $600 \mathrm{~ms}[t(29)=3,802, p<0.01], 600-700 \mathrm{~ms}[t(29)=3.425, p<0.01] ; \mathrm{Pz} 0-100 \mathrm{~ms}$ $[t(29)=-2.065, p<0.05], 200-300 \mathrm{~ms}[t(29)=-4.589, p<0.01], 500-600 \mathrm{~ms}$ $[t(29)=2.431, p<0.05], 600-700 \mathrm{~ms}[t(29)=3.832, p<0.01]$. All other comparisons fell short of conventional levels of significance [all $p$ 's $>0.10$ ].
}

those four windows in terms of ERP amplitude to targets that followed emotional versus neutral distractors.

The Mann-Whitney $U$-test comparing the high and the low depersonalization group in terms of activation at $\mathrm{Fz}, \mathrm{Cz}$, and $\mathrm{Pz}$ for the $0-100 \mathrm{~ms}$ window, 200-300 ms window and the 500-600 ms and $600-700 \mathrm{~ms}$ windows revealed a significant difference between the two groups at $\mathrm{Fz}$ for the $200-300 \mathrm{~ms}$ window [low depersonalization: $M=2.01, S D=2.05$; high depersonalization: $M=0.53, S D=2.11 ; z=-1.97, p<0.05]$. Thus, the high depersonalization group exhibited smaller activation to targets that were preceded by emotional distractors rather than when being preceded by neutral ones. All other comparisons fell short of conventional levels of significance [all $z$ 's $>-1.18$, all $p$ 's $>0.10$ ].

To investigate whether this group difference in ERPs may be due to symptoms or experiences other than depersonalization, Pearson correlations between differences in activation and the DES, CTQ BDI, and STAI-T were calculated (see Table 2). The correlations of these parameters with ERPs in the 200-300 ms window were non-significant, which suggests that depersonalization was specifically related to a lack of differential activation rather than being mediated by symptoms of depression, anxiety or exposure to childhood trauma. Anxiety and depression were, however, associated with a more pronounced differential ERP in the late $600-700 \mathrm{~ms}$ window.

Using forward stepwise linear regression analyses, the contribution of possible predictors other than depersonalization was explored. Mean difference in amplitude between targets preceded by neutral or emotional distractors displayed by the difference wave in the $200-300 \mathrm{~ms}$ window at Fz served as criterion, whereas age, gender, CDS, and its subscales, DES, BDI, STAI, and CTQ served as predictors. Only the CDS Alienation from the Surrounding subscale was significant and accounted for $17 \%$ of the variance in differential amplitude $[B=0.02, S E=0.01$, $\beta=-0.45, t(28)=2.60, p<0.05]$. None of the other factors could significantly improve the prediction.

\section{Discussion}

The main findings of the present study can be summarized as follows. First, replicating the EIB effect reported by Most et al. (2005), targets that were preceded by an emotional distractor at $200 \mathrm{~ms}$ were detected less often than targets that were preceded by a neutral distractor. However, depersonalization was unrelated to this behavioral EIB effect. Second, ERP amplitudes to target stimuli at the frontal and central electrode position reflected by the difference wave in the 200-300 ms window showed a meaningful relationship with the behavioral EIB effect. Specifically, a larger difference wave value was related to a larger EIB effect. Third, individuals with higher levels of depersonalization exhibited less distinct ERP amplitude to targets followed by emotional versus neutral stimuli at the frontal lead in the $200-300 \mathrm{~ms}$ window (as reflected by a smaller difference wave) compared to controls with lower levels of depersonalization. This pattern suggests that at the early stages, the impact of emotional stimuli on target processing is less in persons high on depersonalization than in those low on depersonalization and that this difference is related to an early attentional mechanism. This lack of preferential processing of emotional stimuli is in accordance with prior studies demonstrating that depersonalization is accompanied by aberrations in emotional processing (Giesbrecht et al., 2008b; Giesbrecht et al., 2010; Medford et al., 2006; Phillips et al., 2001; Sierra et al., 2005; Sierra et al., 2002b; Simeon et al., 2008) and with Simeon (2004) who described depersonalization as a state of mental shutdown. Fourth, the regression analysis showed that the relative absence of modulation of ERP's to targets by emotional 
distractors in individuals scoring high on the CDS was related to the Alienation from Surroundings factor of the CDS and not to anxiety. The Alienation from Surroundings factor specifically taps the feeling of being cut off from the environment and contains CDS items such as 'What I see looks 'flat' or 'lifeless', as if I were looking at a picture." One could hypothesize that as emotional stimuli fail to modulate cortical responses, this enhances the feeling of unreality reported by patients with DPD. On the other hand, the regression analysis showed that anxiety and depression were related to modulation of the ERP at Fz between 600-700 ms. Our finding that depersonalization and anxiety are related to modulations of the ERP at different time windows indicates that depersonalization findings are not mediated by co-occurring anxiety and further supports the notion that depersonalization is not just a simple manifestation of anxiety symptoms (Simeon, 2004). The present findings are in line with and extend those of Sierra et al. (2002b, 2006), who found depersonalization to be related to reduced autonomic response to brief emotional negative pictures, but not to neutral or pleasant pictures, and to facial responses of disgust but not to responses to happy faces. In both studies DPD patients differed in this respect from anxious patients, who were comparable to the patients with DPD in terms of anxiety levels. Importantly, in both studies patients did not differ in their ability to recognize and judge the emotionality of the stimuli.

Lemche et al. (2007) used fMRI to investigated processing of emotional faces in DPD patients. These authors found that patients with DPD exhibited decreased activation in the amygdala and hypothalamus and increased activation in the dorsal PFC when viewing sad facial expressions as compared with neutral expressions, while healthy controls showed the opposite pattern.

Several ERP studies have demonstrated that emotional stimuli hold attention and that this effect is modulated by the level of arousal (Cuthbert et al., 2000; Olofsson et al., 2008; Schupp et al., 2006; Schupp et al., 2003; Schupp et al., 2004). Using eventrelated potentials, the present study demonstrates that depersonalization is associated with aberrations in the early phases of emotion processing.

Strikingly, the high and the low depersonalization groups did not differ from each other in correct target detection. In retrospect, this finding seems to be due to the robustness of the EIB effect. Also, previous studies have shown that patients with DPD differ from healthy controls only with regard to some very specific cognitive dimensions, against a general background of normal intellectual ability (Guralnik et al., 2007; Guralnik et al., 2000). Specifically, DPD participants exhibit deficits in visual perception and visual-spatial reasoning for both two- and threedimensional stimuli. Their visual and verbal short-term memory functioning is also compromised, for both abstract and meaningful information, especially under information overload conditions. Furthermore, DPD participants experience difficulty with early stimulus encoding tasks under conditions of heightened distraction to which they respond with more omission errors (lowered perceptual sensitivity). Thus, given the chronicity and severity of depersonalization symptoms in DPD, general cognitive functioning is affected to a surprisingly small extent.

The present study has a number of limitations. First, our study relied on healthy volunteers. Participants in the high depersonalization group were selected because they scored above the cut off that has been proposed by Sierra and Berrios (2000) for the screening of DPD. Yet, the present findings warrant replication, preferably within a sample of DPD patients. Second, as gender was not equally distributed within both groups (11 women and 4 men) and gender differences in emotional processing (for a review see Whittle et al., 2011) are widely acknowledged to exist, one should remain cautious with inferring from the present data that gender differences in the EIB are absent. Thirdly, we strongly relied on self-report measures rather than employing structured interviews to measure depersonalization, anxiety, depression, and childhood trauma. Although our measures are widely used, especially the childhood trauma scale may be subject to context of administration effects leading to both over- and underreporting. Fourth, our controls consisted of individuals scoring relatively low on depersonalization. It would be informative to include anxiety or depressive patients scoring normal on depersonalization in future studies. Fifth, at the behavioral level, we found no indication that high depersonalization scores go along with reduced levels of emotional blindness, although we did observe a frontal ERP pattern suggesting reduced sensitivity to emotionality. Before concluding that depersonalization does not manifest itself at the behavioral level of EIB, it would be good to have more parametric studies on EIB in psychopathology. The point is that the current study closely followed the traditional set-up (Most et al., 2005), but it might be the case that with more intense emotional distractors or with less obvious targets, EIB effects increase for normal controls, but not for individuals scoring high on depersonalization. Finally, we relied on a limited number of electrodes. Future studies using large-array electrodes setting should be performed to replicate and extent that the aberrations in emotional processing linked to depersonalization occur already at the early stages, for example, using source localization.

In sum, the present study demonstrated that individuals scoring high on depersonalization exhibit attenuated modulation of frontal activation by emotional stimuli in the time window of early attentional processing. The present findings contribute to the growing body of evidence showing that the subjective feeling of depersonalization has its neurophysiological concomitants. The present findings in combination with other results demonstrating aberrations in autonomic responding (Sierra et al., 2002a; Sierra et al., 2006) may be helpful when determining laboratory parameters that can be used to evaluate the effects of psychological or pharmacological treatments for depersonalization.

\section{References}

Aderibigbe, Y.A., Bloch, R.M., Walker, W.R., 2001. Prevalence of depersonalization and derealization experiences in a rural population. Social Psychiatry and Psychiatric Epidemiology 36, 63-69.

American Psychiatric Association, 2000. Diagnostic and Statistical Manual of Mental Disorders, 4th ed., revised APA, Washington, D.C.

Beck, A.T., Ward, C.H., Mendelson, M., Mock, J., Erbaugh, J., 1961. An inventory for measuring depression. Archives of General Psychiatry 4, 561-571.

Bernstein, D.P., Stein, J.A., Newcomb, M.D., Walker, E., Pogge, D., Ahluvalia, T. Stokes, J., Handelsman, L., Medrano, M., Desmond, D., Zule, W., 2003. Development and validation of a brief screening version of the childhood trauma questionnaire. Child Abuse and Neglect 27, 169-190.

Cacioppo, J.T., Tassinary, L.G., Berntson, G.G., 2007. Handbook of Psychophysiology. Cambridge University Press.

Cuthbert, B.N., Schupp, H.T., Bradley, M.M., Birbaumer, N., Lang, P.J., 2000. Brain potentials in affective picture processing: covariation with autonomic arousal and affective report. Biological Psychology 52, 95-111.

Delorme, A., Makeig, S., 2004. EEGLAB: an open source toolbox for analysis of single-trial EEG dynamics. Journal of Neuroscience Methods 134, 9-21.

Giesbrecht, T., Lynn, S.J., Lilienfeld, S.O., Merckelbach, H., 2008a. Cognitive processes in dissociation: an analysis of core theoretical assumptions. Psychological Bulletin 134, 617-647.

Giesbrecht, T., Merckelbach, H., ter Burg, L., Cima, M., Simeon, D, 2008b. Acute dissociation predicts rapid habituation of skin conductance responses to aversive auditory probes. Journal of Traumatic Stress 21, 247-250.

Giesbrecht, T., Merckelbach, H., van Oorsouw, K., Simeon, D., 2010. Skin conductance and memory fragmentation after exposure to an emotional film clip in depersonalization disorder. Psychiatry Research 117, 342-349.

Guralnik, O., Giesbrecht, T., Knutelska, M., Sirroff, B., Simeon, D., 2007. Cognitive functioning in Depersonalization Disorder. Journal of Nervous and Mental Disease 195, 983-988.

Guralnik, O., Schmeidler, J., Simeon, D., 2000. Feeling unreal: cognitive processes in depersonalization. American Journal of Psychiatry 157, 103-109.

Hagemann, D., 2004. Individual differences in anterior EEG asymmetry: methodological problems and solutions. Biological Psychology 67, 157-182. 
Lang, P.J., Bradley, M. M., Cuthbert, B. N., 1999. International Affective Picture System (IAPS): Instruction Manual and Affective Ratings: Technical Report A-4. Center for Research in Psychophysiology, University of Florida, Gainesville, FL.

Lee, W.E., Kwok, C.H.T., Hunter, E.C.M., Richards, M., David, A.S., 2012. Prevalence and childhood antecedents of depersonalization syndrome in a UK birth cohort. Social Psychiatry and Psychiatric Epidemiology 47 (2), 253-261.

Lemche, E., Surguladze, S.A., Giampietro, V.P., Anilkumar, A., Brammer, M.J., Sierra, M., Chitnis, X., Williams, S.C., Gasston, D., Joraschky, P., David, A.S., Phillips, M.L., 2007. Limbic and prefrontal responses to facial emotion expressions in depersonalization. Neuroreport 18, 473-477.

Luck, S.J., Woodman, G.F., Vogel, E.K., 2000. Event-related potential studies of attention. Trends in Cognitive Sciences 4, 432-440.

Medford, N., Brierley, B., Brammer, M., Bullmore, E.T., David, A.S., Phillips, M.L., 2006. Emotional memory in depersonalization disorder: a functional MRI study. Psychiatry Research 148, 93-102.

Miller, G.A., Lutzenberger, W., Elbert, T., 1991. The linked-reference issue in EEC and ERP recording. Journal of Psychophysiology 5, 276.

Most, S.B., Chun, M.M., Widders, D.M., Zald, D.H., 2005. Attentional rubbernecking: cognitive control and personality in emotion-induced blindness. Psychonomic Bulletin \& Review 12, 654-661.

Nummenmaa, L., Hyona, J., Calvo, M.G., 2006. Eye movement assessment of selective attentional capture by emotional pictures. Emotion 6, 257-268.

Olofsson, J.K., Nordin, S., Sequeira, H., Polich, J., 2008. Affective picture processing: an integrative review of ERP findings. Biological Psychology 77, 247-265.

Phillips, M.L., Medford, N., Senior, C., Bullmore, E.T., Suckling, J., Brammer, M.J., Andrew, C., Sierra, M., Williams, S.C.R., David, A.S., 2001. Depersonalization disorder: thinking without feeling. Psychiatry Research-Neuroimaging 108, 145-160.

Schupp, H., Flaisch, T., Stockburger, J., Junghofer, M., 2006. Emotion and attention: event-related brain potential studies. Journal of Psychophysiology 20, 115.

Schupp, H.T., Junghofer, M., Weike, A.I., Hamm, A.O., 2003. Attention and emotion: an ERP analysis of facilitated emotional stimulus processing. Neuroreport 14, 1107-1110.

Schupp, H.T., Junghofer, M., Weike, A.I., Hamm, A.O., 2004. The selective processing of briefly presented affective pictures: an ERP analysis. Psychophysiology 41, 441-449.

Semlitsch, H., Anderer, P., Schuster, P., Presslich, O., 1986. A solution for reliable and valid reduction of ocular artifacts, applied to the P300 ERP. Psychophysiology $23,695-703$.
Sierra, M., Baker, D., Medford, N., David, A.S., 2005. Unpacking the depersonalization syndrome: an exploratory factor analysis on the Cambridge Depersonalization Scale. Psychological Medicine 35, 1523-1532.

Sierra, M., Berrios, G.E., 1998. Depersonalization: neurobiological perspectives. Biological Psychiatry 44, 898-908.

Sierra, M., Berrios, G.E., 2000. The Cambridge Depersonalisation Scale: a new instrument for the measurement of depersonalisation. Psychiatry Research 93, 163-164.

Sierra, M., Lopera, F., Lambert, M.V., Phillips, M.L., David, A.S., 2002a. Separating depersonalisation and derealisation: the relevance of the "lesion method. Journal of Neurology, Neurosurgery and Psychiatry 72, 530-532.

Sierra, M., Senior, C., Dalton, J., McDonough, M., Bond, A., Phillips, M.L., et al., 2002b. Autonomic response in depersonalization disorder. Archives of General Psychiatry 59, 833-838.

Sierra, M., Senior, C., Phillips, M.L., David, A.S., 2006. Autonomic response in the perception of disgust and happiness in depersonalization disorder. Psychiatry Research 145, 225-231.

Simeon, D., 2004. Depersonalisation disorder: a contemporary overview. CNS Drugs 18, 343-354.

Simeon, D., Abugel, J., 2006. Feeling Unreal: Depersonalization Disorder and the Loss of the Self. Oxford University Press, Oxford.

Simeon, D., Guralnik, O., Schmeidler, J., Sirof, B., Knutelska, M., 2001. The role of childhood interpersonal trauma in depersonalization disorder. American Journal of Psychiatry 158, 1027-1033.

Simeon, D., Kozin, D.S., Segal, K., Lerch, B., Dujour, R., Giesbrecht, T., 2008. Deconstructing depersonalization: further evidence for symptom clusters. Psychiatry Research 157, 303-306.

Spielberger, C.D., 1983. The State-Trait Anxiety Inventory (STAI). Consulting Psychologists Press, Palo Alto, CA.

van IJzendoorn, M.H., Schuengel, C., 1996. The measurement of dissociation in normal and clinical populations: meta-analytic validation of the dissociative experience scale (DES). Clinical Psychology Review 16, 365-382.

Vuilleumier, P., 2005. How brains beware: neural mechanisms of emotional attention. Trends in Cognitive Sciences 9, 585-594.

Whittle, S., Yucel, M., Yap, M.B., Allen, N.B., 2011. Sex differences in the neural correlates of emotion: evidence from neuroimaging. Biological Psychology $87,319-333$. 